\title{
Stimulation and Maintenance in the Construction of Digital Learning Resources: A Study of Online Learners' Learning Interests
}

\author{
Xiao Yin \\ Zhejiang Open University, Hangzhou, China \\ Email: 357139169@qq.com
}

How to cite this paper: Yin, X. (2021) Stimulation and Maintenance in the Construction of Digital Learning Resources: A Study of Online Learners' Learning Interests. Open Access Library Journal, 8: e7595. https://doi.org/10.4236/oalib.1107595

Received: May 28, 2021

Accepted: July 17, 2021

Published: July 20, 2021

Copyright (c) 2021 by author(s) and Open Access Library Inc.

This work is licensed under the Creative Commons Attribution International License (CC BY 4.0).

http://creativecommons.org/licenses/by/4.0/

\section{(c) (i) Open Access}

\begin{abstract}
With the rapid development of network technology and multimedia technology, especially in the special environment of 2020, online learning has become one of the main learning methods under the digital learning environment. At the same time, in the process of constructing digital learning resources, online learners are prone to new problems such as loss of focus and fluctuation of learning effect. How to fundamentally stimulate and maintain the learning interest of online learners in the process of constructing digital learning resources has become an urgent problem to be solved. Based on the problem-oriented approach and the comprehensive application of in-depth interview method and other research methods, this paper finds out four major problems affecting learning interest based on the in-depth analysis of the basic characteristics and learning status of online learning in the construction of digital learning resources. This paper analyzes the reasons and puts forward solutions from three aspects: scientific design and development of resources, active and effective incentive strategies, and rich resource construction paths, so as to provide useful references for stimulating and maintaining online learners' interest in learning in the construction of digital learning resources.
\end{abstract}

\section{Subject Areas}

E-Learning and Knowledge Management

\section{Keywords}

Construction of Digital Learning Resources, Stimulate, Keep, Online Learning, Interest Research 


\section{Introduction}

Online learning is the essence of digital learning environment using digital learning resources for online learning, by providing a large number of learning resources, learning methods and learning tools, broke the traditional learning mode in time and space and the limits of teaching content, can make the learners can choose according to their own actual situation of learning time, place and content, to a great extent, it meets the personalized learning needs of students and expands the boundaries of learning. New learning model, however, also poses a new challenge, because of the lack of monitoring and evaluation method, the digital learning environment uncertainty about online learning behavior, learning is very difficult to guarantee, between the individual difference is very big, to some extent, affected the development of online learning, how to arouse in the process of digital learning resources construction and keep the online learners' interest in learning, it has become a problem to be faced in the construction of digital learning resources.

\section{Basic Characteristics of Online Learning under Digital Learning Environment}

The famous scholar Desmond Kegon once summarized the basic characteristics of digital online learning, namely:

\subsection{Separation of Learning Resources and Learners}

In the whole learning process, teaching resources and learners are in a state of "quasi-separation", but the degree of separation is different.

\subsection{The Role of Teaching Organization}

To provide an institutionalized education, which is fundamentally different from the spontaneous, unorganized self-study of learners.

\subsection{Application of Technical Media}

The application of technical media provides communication tools such as interactive television, video (audio, video), computers and the Internet. Technical media can benefit students by connecting "quasi-detached" learners with learning resources and delivering teaching content.

\subsection{Provide Two-Way Communication}

Two-way communication is an important factor that distinguishes distance education from the one-way application of pure media technology.

\subsection{Separation of Learning and Learning Groups}

There is no traditional form of student collective, but only virtual form of student collective, virtual class or virtual community, but it is not mandatory for 
learners to join the learning collective, which is also an important feature different from conventional classroom education [1].

\section{The Status Quo of Online Learning in the Digital Learning Environment}

The analysis and in-depth investigation and prediction report of China's online education industry from 2015 to 2020 shows that with the rapid development of network technology, the number of learners adopting online learning is gradually increasing, and online learning has become the main channel for the industrialization development of education and one of the research hotspots in distance education and other fields [2]. In this paper, a total of 25 interviewees were interviewed in depth, and each interviewee lasted about 30 minutes. In terms of the selection of interviewees, in order to ensure that the interviewees are widely representative, 5 of them are administrators of relevant websites and 20 are online learners. In terms of interview structure, this paper mainly use structured interviews, neither a pre-decided interview outline, not strictly limit the conversation, around the topic, to encourage respondents to the freedom of expression, according to oneself circumstance can easily insight interview object to concern problems of online learning experience, as well as the countermeasures and Suggestions. According to the interview results, summarize the status quo of online learning from six aspects.

\subsection{Study Time Is Flexible and Free}

The teaching method of online learning platform is different from the traditional teaching method. In this way, the course provider uplods the learning resources to a fixed website in advance. After the learner registers on the website and logs in his/her personal learning account, he/she can get all the teaching resources of the website. Learners can choose interest courses for online learning according to their own needs. In addition, the flexibility of learning time and place is a great advantage of online learning platform, breaking the traditional teaching schedule according to the schedule of the restriction, you can learn anytime and anywhere, no longer rigor fixed teaching place.

\subsection{Personalization of Learning Content}

The online learning method based on video teaching has greatly improved the learning efficiency of learners, and learners can adjust their learning state independently according to their own personal situation. For example, in the process of learning to encounter difficult knowledge points or more complex reasoning calculation, learners can stop at any time to think, consult information or take notes. According to the survey, the development of online learning is also beneficial to have a high demand for their high level learners, they get many famous universities at home and abroad through online learning platform of quality courses, such as the United States at Harvard University, Columbia University, 
and domestic Tsinghua university, Beijing university and so on, this is way past the traditional teaching cannot realize and solve the problem. Online learning platforms have greatly increased the channels for learners to acquire knowledge, integrating teaching videos and teaching materials from all walks of life to meet the needs of all types of people.

\subsection{The Cost of Learning Is Economical and Applicable}

Online teaching platform can not only rely on the network to spread the teaching videos to students all over the world, but also can keep the uploaded teaching videos for a long time for learners to watch later. For learners, online teaching platforms can provide an electronic version of the lecture notes, so it is not necessary to have a textbook for everyone. For teachers, they only need to record their courses and put them on the network platform, so that they can be watched by learners all over the world for an unlimited number of times. The number of learners is not limited, and the teaching content need not be repeated. In this way, there are no high learning costs and a variety of textbook printing costs, from a large extent to reduce the cost of learning.

\subsection{Innovate New Learning Modes}

Online learning carrier and mode with the development of learners' demand changes are, for example: close to the traditional teaching methods of video broadcast "mode of TV University", the answer will be taught online and offline distinguish "double model" and the latest, increase the interaction between teachers and students, and participatory model of "artificial intelligence" class. With the development of science and technology, the online learning model is increasingly catering to the needs of learners.

\subsection{Learning System Problems Appear}

Because the system intelligence of online learning platform is not perfect, it can not meet the individual needs of some colleges and universities and learners. Different from traditional classroom teaching methods, online learning platforms have no teacher's supervision in the learning process and are completely dependent on the consciousness of learners. Therefore, they have higher requirements on learners' self-initiative and self-regulation ability. In addition, online learning still needs to improve the learning atmosphere, and strive to reduce the sense of loneliness and helplessness of learners, and create a collective learning environment.

\subsection{The Number of Online Users Is Increasing Year by Year}

The status quo of online learning shows that a variety of online learning APPs have entered people's learning and life, and are gradually promoted as "magic tools" for learning, which is unanimously welcomed and praised by most young users. Under this development trend, the number of online learning users will 
grow at a faster speed, and the scale of online education market is expected to reach 433 billion yuan in 2020 [3].

\section{Advantages of the Construction of Digital Learning Resources in Stimulating and Maintaining Learning Interest}

Compared with traditional learning methods, digital online learning can stimulate learners' interest in learning and improve learning quality to a certain extent for the following reasons.

\subsection{Cater to Your Learning Preferences}

Although different types of online learners may have different learning preferences, diverse forms, relaxed atmosphere, convenience and efficiency are the most common requirements. First of all, the advent of the Internet era has provided new ways and unlimited possibilities for online learners. The human-computer interaction mode based on AI algorithm was unimaginable in the past. New media technology plays a key role in online learning. All kinds of learning resources integrate images, videos, audio, etc. The content is rich and varied, vivid and intuitive, which not only arouses the enthusiasm of learners, but also helps deepen the impression. Secondly, online learning avoids the tension of face-to-face communication in traditional classroom teaching, so that learners can freely express and show themselves and become more subjectivity in learning. This can be seen from the fact that the number of people who take the initiative to speak up in online learning is significantly more than that in offline learning [4].

\subsection{Arouse Enthusiasm for Learning}

Influenced and restricted by the traditional learning mode, in today's offline learning, some teachers are still accustomed to adopting the instillation teaching mode and guiding students to learn mechanically, which is easy to cause the resistance of learners. In today's era of information explosion, people are constantly exposed to new things, but few of them are unaffected by them. Most learners are easily immersed in them, which distracts their interest and attention in learning. And online learning, a novel interactive mode, is the new thing in the eyes of the tide. Whether it is $\mathrm{AR}, \mathrm{VR}$ or simple human-computer interaction, this kind of simulated language environment created by new media technology effectively strengthens the interactivity of online learning, greatly increases the interest of learning and stimulates the enthusiasm of learning.

\subsection{Enhance Learning Ability}

China's traditional teacher-taught traditional teaching model has not changed much since ancient times. The rapid development of Internet technology has not changed the traditional teaching model in essence. Most offline teaching is still 
based on teachers' teaching, and learners passively accept it, and lack the ability of active learning and autonomous learning. In order to improve learning ability, we have to reverse the traditional teacher-student relationship in learning activities, so the concept of flipped classroom arises at the historic moment [5]. This concept originated in the United States, is widely used in recent years, turn to adjust the traditional relationship between teachers and students in the classroom, teachers are no longer dominate, the active participation of students under the guidance of teachers' teaching, as the main body of teaching activity, teachers focus on observing the students' learning situation and analysed, adjust teaching way. Flipped classroom is not only a reflection on traditional teaching concepts, but also a teaching method dominated by students' independent learning. Online teaching exactly meets all the elements of flipped classroom, and students are the absolute main body of online learning. Whether it is big data algorithm or massive resource database, calculation and analysis are conducted according to students' learning ability and learning progress, and personalized learning programs are provided to guide students to learn independently. Students decide whether or not they want to learn and what they want to learn. Even if it is a cloud class broadcast by the teacher, students can simply turn off the screen if they think it is not appropriate. The entire process of online learning is a student's choice. Online learning gives students more choice, more power to choose, and more subjective initiative. The biggest advantage of online learning is to cultivate students' independent learning habits and the ability to plan their time, guide students to change from "I want to learn" to "I want to learn", and truly learn spontaneously.

\section{Problems Affecting Learning Interest in the Digital Learning Environment}

\subsection{Four Main Problems}

In the digital learning environment, there are many factors affecting the effect of students' online learning. It needs to be performance-oriented and classified in detail from multiple dimensions, such as learners' basic information, learning path, learning resource utilization information, online interactive behavior information, etc. Among them, basic information of learners includes basic personal information and basic academic information. Learning path can directly reflect the real learning process of learners, and is of great significance for optimizing learning, providing learning assistance and adjusting teaching strategies [6]. Learning resource utilization information refers to the number of downloads, browsing times and reading duration of online digital learning resources of learners, which reflects the characteristics of learners' needs for course learning and has certain statistical significance. Online interactive behavior information mainly includes learners' behaviors such as Posting replies, initiating topics and commenting on the forum, which can reflect learners' learning state to a certain extent. In addition, effective communication between teachers and stu- 
dents and students through online forums and other environments can also significantly improve the learning effect of learners. From the above perspectives, it can be concluded that there are mainly the following problems that affect the online learning effect of students:

\subsubsection{Time for Filtering Resources}

Learners' learning process is a reprocessing process of knowledge. Only when they have an understanding of the process of knowledge transmission can they learn knowledge better. It is found that online learning is an important way to disseminate and acquire knowledge. In the process of online learning, learners need to spend a lot of time to select learning resources, and the final selection of learning resources may not meet their learning needs, time-consuming and laborious, the learning effect is not good. However, if learners are weak in information screening, they will not know which resource is suitable for them when faced with similar resource information, so they will vacillate between multiple resources and increase the searching time. If there are problems such as large amount of resources, unclear classification, unclear description of resources, low resource rating, no perfect evaluation mechanism and reasonable recommendation mechanism, and incomplete historical data analysis, learners will be misled and their resource search time will be increased [7].

\subsubsection{Overreliance on the Internet}

There is no doubt that online learning is completely dependent on the Internet, and the whole learning process is also very dependent on the network. Disconnection and lag caused by poor network will be a great waste of learning time. Once the online learning platform fails or is taken down, users will completely lose learning resources and their learning plans will be completely disrupted.

\subsubsection{Health Problems}

Mobile phones, computers, tablets and other electronic devices, as the mainstream media of online learning, not only promote the development of online learning, but also cause a series of health problems, such as myopia, cervical pain, lumbar disc herniation and so on. Since online learning requires sitting for a long time, staring down at the mobile phone, and there is no mandatory time arrangement for classes and breaks, learners tend to study continuously for a long time, and irregular work and rest patterns may cause excessive wear and tear on the body and cause discomfort.

\subsubsection{Too Many Interference Factors}

Although online learning resources are a major advantage of online learning, in order to achieve profits, various learning resources usually insert all kinds of advertisements or inductive publicity, and even illegal website links involving pornography, gambling and drugs. There are too many uncertain and disturbing factors on the network, which makes it difficult for people to concentrate on learning. Learners, represented by students, have full capacity for civil conduct, 
but they have not set foot in the society, lack of experience and concentration. Out of curiosity, they get out of hand when they open it intentionally or unintentionally. Instead of improving the learning effect, they are prone to indulge in things unrelated to learning [8].

\subsection{Cause Analysis of the Problems}

1) Due to weak constraints on learning time and learning behavior, participation and learning efficiency may be low. Due to the lack of periodic encouragement of sense of achievement, learners' learning motivation is difficult to gradually strengthen.

2) Low awareness of management rules, poor communication, low recognition, weak conditionality of management regulations and norms.

3) Lack of on-site control and control means for adverse phenomena and weak immediate correction.

4) Insmooth information transmission and lack of effective means of inquiry add some trouble to learners' learning activities.

5) The quality of live broadcast platforms is uneven, and the control ability of managers is limited.

6) The indirection and hysteresis of network interaction make students' communication consciousness attenuate with the decrease of communication efficiency.

7) Dispersion of online discussion topics leads to cognitive confusion, learners tend to deviate from the main logical train of thought, and it is difficult for teachers to correct the deviation.

8) It is difficult to grasp the effectiveness of assessment, and the difficulty and scale of evaluation are different.

9) Online learning lacks group atmosphere, learners' sense of belonging is low, their sociality cannot be satisfied, and they tend to have a sense of loneliness.

\section{Suggestions to Improve Interest in Online Learning}

\subsection{Scientific Design and Development of Online Resources}

Large-scale popularization and use of online learning to a new challenge to the design of digital learning resources, new thinking and new curriculum design requirements, at the same time, also for online learning points out the problems of the teaching of the course design, target, solution and solutions, in summary, online resources design and development need to follow the principle of three aspects.

\subsubsection{Design Online Learning Resources around the Core Issues of the Course}

Focusing on the significance and value of online learning resources is that it can trigger learners to think about the core problems of the course and help learners to find solutions to the core problems of the course. Resources must reflect their focus on the core issues. Therefore, in addition to designing the most basic 
learning resources related to knowledge points for learners, learning resources and cognitive tools must also be designed around the core issues of the course, so that learners can improve their understanding depth and problem-solving ability in the process of independent learning.

\subsubsection{Design Online Learning Resources in an Appropriate Form}

Common online learning resources include various forms of resources, such as text, pictures, tables, diagrams, web links, audio and video, test questions, gauges, courseware, lesson plans, electronic textbooks, etc. The development of information technology and media technology has also spawned the formation of new online learning resources, such as micro-video, simulation (VR and AR), MOOC courses, etc. [9]. Each online learning resource can deliver certain teaching information, and there is no superior or inferior one. The resources must reflect their adaptability to learning activities. Excessive pursuit of technical difficulty and development intensity will not only increase the development cost and prolong the development cycle, but also increase the cognitive load of learners and distract their attention from learning, resulting in more gain than loss.

\subsubsection{Select Appropriate Ways to Generate Online Learning Resources}

Under the information technology environment, the most convenient is the acquisition of information. The Internet and mobile phones can almost meet all the needs of users. So the development of online learning resources has shifted to the collection and organization of information. The development of online learning resources can be original design and development by teachers according to the needs of online learning, that is, independent development, extensible design or online collection, generative design or real-time dynamic design.

In the specific development of online learning resources, designers need to choose appropriate ways to design certain forms of online learning resources based on the nature of the core problems of the course. Resources such as original design pictures, diagrams and concept maps can help learners to understand the relationship between concepts and other cognitive activities. Network resource links, electronic textbooks, MOOC courses and other resources can help learners broaden their horizons and solve the core problems of the course. Micro video, simulation and other resources can help learners master procedural or step-by-step knowledge; Generative resources such as dynamic diagrams and data tables for teacher-student interaction can help learners master strategic knowledge such as decision-making, strategies, techniques or algorithms in real time, thus effectively increasing learners' interest.

\subsection{Adopt Positive and Effective Incentive Strategies}

\subsubsection{Constantly Update Online Learning Resources}

At present, through the continuous exploration of online teaching mode, the various portal websites have a full understanding of the advantages and disadvantages of online learning. In fact, the content and even the use of language 
have the potential to be outdated, so the learner will not be interested in all the content and want to challenge it. Many video websites provide the latest learning resources. While these videos are vivid and practical, the theme is also very clear. Designers can guide learners to learn supplementary materials in videos according to their different receptivity, as an extension of classroom learning.

\subsubsection{Continuously Enrich the Forms of Independent Learning}

Most online learners are self-directed, and this is a skill that most students need to develop. Self-directed learning is a step-by-step process, with the ultimate goal of eliminating the influence of the course itself, that is, whether there is a teacher teaching it or not, which teacher teaches it will not affect students' learning in the end. The advantage of autonomy is reflected in its driving effect on learning, and it is also the key factor to stimulate learning motivation and improve learning interest. And people's attitudes toward learning tasks tend to be more positive as the number of choices increases. Allowing learners to choose their favorite teaching resources, such as online articles, blogs, and videos, not only gives them a sense of trust, but also increases their interest in learning. Learners should allow themselves to decide what form to use when presenting their learning results, such as short videos, audio recordings, slides, etc. Learners often encounter a kind of confusion in learning, that is, when they try very hard to do this thing but can not make progress, their confidence and motivation to move forward will be seriously hit. Therefore, if learners can choose their own learning materials and learning methods, and trust that their learning ability can help them understand and complete the learning task, autonomous learning has already achieved more than half the success. Therefore, in order to stimulate learners' learning motivation, online resource providers should attach importance to and play a guiding role in helping to tap a variety of learning resources and expand learning forms.

\subsubsection{Provide a Network Communication Platform Continuously}

One of the most basic human needs is the relationship need, which is the content of self-determination theory, which suggests that the key to happiness is effective connection with others, especially in the current or wider social context. QQ, WeChat, Staidu and other diversified online communication tools, greatly reducing the cost of communication, but also shorten the distance between people. In the traditional classroom teaching activities, there are frequent communication between teachers and students, and students can easily gain a sense of identity, which is the internal driving force for persisting in learning. Online learning, however, is usually done by students alone. Even if they show their learning results online, they cannot immediately gain recognition. So need based on the current mainstream communication tool for learners to build network communication platform, learners can freely share on the platform to show their results of online learning, timely access to identity the also formed a study upsurge in cyberspace, and such learning boom will help in the long term online 
learning. When learners encounter problems in online learning, they can also seek help from teachers or classmates through these online communication platforms to improve their interest in learning and learning efficiency.

\subsection{Enrich the Path of Construction of Digital Learning Resources}

\subsubsection{Increase Investment}

Under the background of "Internet+", the construction of digital learning resources requires all kinds of resource providers to actively expand the fund-raising path and ensure the intensity of investment in the construction of digital learning resources. In the process of promoting the construction of digital resources, capital investment is the foundation, which requires a lot of human resources, material resources and financial resources. At the present stage, many resource providers, especially universities and other research institutions, have set up special funds for the construction of digital teaching resources, but problems such as insufficient investment and uneven allocation of funds will inevitably exist only depending on the financial support of the state [10]. Therefore, universities and other research institutions should strengthen cooperation with social enterprises, expand funding sources for digital resource construction, and supplement talents with practical experience for digital construction through school-enterprise cooperation mode. In the process of cooperation with social enterprises, the established interests that enterprises can obtain should be clearly defined, such as providing high-quality talents to enterprises and cooperating in running schools, so as to effectively mobilize enterprises' interest and initiative in participating in the construction of digital resources. At the same time, while receiving government financial support and absorbing private capital, universities and other research institutions should actively improve their "hematopoietic ability", introduce market mechanism, open the school education market under the guidance of government departments, and strengthen the investment in digital construction [11].

\subsubsection{Integration of Educational Resources}

At present, in the construction of digital resources, there is a shortage of high-quality resources, and there are many low-level and repeated constructions, which can hardly meet the learning needs of learners for digital resources. To construct digital resources, we should make full use of and integrate existing teaching resources and create an environment for sharing educational resources. First of all, all kinds of online websites can build cooperative relationships with all kinds of professional institutions, make full use of their high-quality educational resources, excavate rich digital teaching content, create a highly shared mechanism of digital learning resources, and avoid the occurrence of repeated construction of digital learning resources. Secondly, the construction of digital resources should also fully acquire the knowledge sharing content of learners, integrate learners' learning experience and sharing of learning resources with the help of big data technology and cloud platform, so as to promote the accumula- 
tion of digital resources. Finally, the construction of digital learning resources under the background of "Internet+" is based on the construction of a website learning platform. Digital learning websites will provide learners with rich and large learning resources, and realize the combination of all kinds of tangible resources and intangible resources. The construction of network resource-cluster websites has become the key content.

\subsubsection{Strengthen Technical Training}

Under the background of "Internet+", the construction of digital learning resources and the strengthening of digital technology training mainly involve two subjects, namely resource providers and learners. First of all, in the construction of digital resources, the low level of production technology and low learning ability are the main limiting factors. Technical training for resource providers is mainly to adopt various forms of training to enhance professional ability. For example, special lectures, temporary training, practical training and so on. At the same time, the construction of digital learning application support system should be strengthened to ensure the optimization and maximization of the utilization efficiency of digital learning resources. Secondly, we should pay attention to the cultivation of learners' digital ability and improve their awareness and ability of using digital learning resources. It can be carried out by means of publicity and guidance, combined with incentives to stimulate learners' enthusiasm for learning and enhance their confidence in using.

\section{Conclusion}

The vigorous development of online learning is not only the inner demand of learners, but also the external requirement of the change of times. In learning mode under the background of change, it is necessary to take effective measures to actively learn from various advanced online media means, we will further improve the design and development of online resources, rich resources, and effectively stimulate the learners' online learning driving force, so that the students from passive to accept into autonomous learning, online teaching vigorous development, promote better learning effect.

\section{Conflicts of Interest}

The author declares no conflicts of interest.

\section{References}

[1] Yang, D. (2016) Research on the Current Situation and Countermeasures of Residents' Digital Learning from the Perspective of "Internet+"-Taking "Promoting Residents' Digital Learning in Nanfeng Town" as an Example. Journal of Shandong Radio and TV University, No. 3, 17-19.

[2] Song, Q.H. (2016) Research on the Construction of Regional Digital Lifelong Learning Platform in the Perspective of "Internet+"-Based on the Investigation and Analysis of the Construction of Digital Learning Platform in Shanghai. China Adult Education, No. 15, 10-12. 
[3] Cui, M., Mu, S. and Huang, X.D. (2020) Research on Online Learning Paths Based on Process Data and Analysis: Rules and Planning. Open Education Research, 26, 58-70.

[4] Hu, J.P. (2020) "Internet+" Research on the Professional Development of College English Teachers in the Times-Based on the Perspective of Multi-Modal Teaching Model. Journal of Jiangxi Radio and Television University, 22, 60-65.

[5] Liu, X.Y. (2019) A Study on College English Teaching Strategies in the Era of Internet+. Intelligence, 4, 33.

[6] Li, T.T. (2020) Practice and Thinking of Online English Teaching in Higher Education Colleges during COVID-19 Epidemic Prevention and Control. Teaching in Forest Region, No. 6, 66-68.

[7] Chen, G., Gao, T., Zhu, X., et al. (2017) Personalized Recommendation Based on Single Bidirectional Mass Diffusion. Physica A: Statistical Mechanics and Its Applications, 469, 397-404. https://doi.org/10.1016/j.physa.2016.11.091

[8] Zou, C., Zhang, D., Wan, J., et al. (2015) Using Concept Lattice for Personalized Recommendation System Design. IEEE Systems Journal, 11, 1-10.

[9] Yang, C., Fan, Q., Wang, T., et al. (2019) RepoLike: A Multi-Feature Based Personalized Recommendation Approach for Open-Source Repositories. Frontiers of Information Technology \& Electronic Engineering, 20, 86-101. https://doi.org/10.1631/FITEE.1700196

[10] Zhang, J., Zeng, X., Liu, K., et al. (2018) Jeans Knowledge Base Development Based on Sensory Evaluation Technology for Customers' Personalized Recommendation. International Journal of Clothing Science and Technology, 30, 101-111. https://doi.org/10.1108/IJCST-03-2017-0036

[11] Hao, T. (2017) Personalized Service Recommendation Based on Trust Relationship. Scientific Programming, 2017, Article ID: 4106134.

https://doi.org/10.1155/2017/4106134 